\title{
Age-Related Tau Burden and Cognitive Deficits Are Attenuated in KLOTHO KL-VS Heterozygotes
}

Ira Driscoll ${ }^{\mathrm{a}, \mathrm{b}, \mathrm{c}}$, Yue Ma ${ }^{\mathrm{b}}$, Catherine L. Gallagher ${ }^{\mathrm{d}, \mathrm{e}}$, Sterling C. Johnson Sterling ${ }^{\mathrm{a}, \mathrm{b}, \mathrm{d}}$, Sanjay Asthana ${ }^{\mathrm{a}, \mathrm{b}, \mathrm{d}}$, Bruce P. Hermann ${ }^{\mathrm{a}, \mathrm{b}, \mathrm{e}}$, Mark A. Sager ${ }^{\mathrm{a}, \mathrm{b}}$, Kaj Blennow ${ }^{\mathrm{f}, \mathrm{g}}$, Henrik Zetterberg ${ }^{\mathrm{f}, \mathrm{g}, \mathrm{h}, \mathrm{i}}$, Cynthia M. Carlsson ${ }^{\mathrm{a}, \mathrm{b}, \mathrm{d}}$, Corinne D. Engelman ${ }^{\mathrm{a}, \mathrm{b}, \mathrm{j}}$, Dena B. Dubal ${ }^{\mathrm{k}}$ and Ozioma C. Okonkwo ${ }^{\mathrm{a}, \mathrm{b}, \mathrm{d}}$

${ }^{a}$ Wisconsin Alzheimer's Disease Research Center, University of Wisconsin-Madison, Madison, WI, USA

${ }^{\mathrm{b}}$ Wisconsin Alzheimer's Institute, Madison, WI, USA

${ }^{\mathrm{c}}$ Department of Psychology, University of Wisconsin-Milwaukee, Milwaukee, WI, USA

${ }^{\mathrm{d}}$ Geriatric Research Education and Clinical Center, William S. Middleton VA Hospital, Madison, WI, USA

${ }^{\mathrm{e}}$ Department of Neurology, University of Wisconsin School of Medicine and Public Health, Madison, WI, USA

${ }^{\mathrm{f}}$ Department of Psychiatry and Neurochemistry, Institute of Neuroscience and Physiology, Sahlgrenska Academy at the University of Gothenburg, Göteborg, Sweden

${ }^{\mathrm{g}}$ Clinical Neurochemistry Laboratory, Sahlgrenska University Hospital, Mölndal, Sweden

${ }^{\mathrm{h}}$ Department of Neurodegenerative Disease, UCL Institute of Neurology, Queen Square, London, UK

${ }^{i} U K$ Dementia Research Institute at UCL, London, UK

${ }^{\mathrm{j}}$ Departments of Population Health Sciences, University of Wisconsin School of Medicine and Public Health, Madison, WI, USA

${ }^{\mathrm{k}}$ Department of Neurology and Weill Institute for Neurosciences, University of California, San Francisco, CA, USA

Pre-press 5 July 2021

[Journal of Alzheimer's Disease, 79 (3) (2021), 1297-1305 DOI 10.3233/JAD-200944]

https://content.iospress.com/articles/journal-of-alzheimers-disease/jad200944

On p. 1299, in the Results section, where it says:

We have also assessed how many of the participants in this sample would be considered abnormal or negative based on our center's derived cutpoint for CSF AD biomarkers [32], namely A $\beta_{42}(\leq 471.54)$, pTau $(\geq 59.5)$, and tTau $(\geq 461.26)$. Majority of the participants in our sample were negative for both $A \beta$ and tau biomarkers. Based on $\chi^{2}$-tests, the percentage of those who were $\mathrm{A} \beta_{42}$ negative did not significantly differ between KL-VS heterozygotes (7\%) versus non-carriers (12\%) $(p=0.18)$. Similarly, the percentage of those who were negative based on pTau did not significantly differ between KL-VS heterozygotes $(18 \%)$ and non-carriers $(13 \%)(p=0.27)$. Finally, based on the tTau measure, the percentage of those who were negative did not significantly differ between KL-VS heterozygotes $(16 \%)$ and noncarriers $(14 \%)(p=0.42)$. 
It should be:

We have also assessed how many of the participants in this sample would be considered positive (i.e., abnormal) based on our center's derived cutpoint for CSF AD biomarkers [32], namely A $\beta_{42}(\leq 471.54)$, pTau $(\geq 59.5)$, and tTau $(\geq 461.26)$. Majority of the participants in our sample were negative for both $\mathrm{A} \beta_{42}$ and tau biomarkers. Based on $\chi^{2}$-tests, the percentage of those who were $A \beta_{42}$ positive did not significantly differ between KL-VS heterozygotes (7\%) versus non-carriers (12\%) $(p=0.18)$. Similarly, the percentage of those who were positive based on pTau did not significantly differ between KL-VS heterozygotes $(18 \%)$ and non-carriers $(13 \%)(p=0.27)$. Finally, based on the tTau measure, the percentage of those who were positive did not significantly differ between KL-VS heterozygotes (16\%) and non-carriers (14\%) $(p=0.42)$. 